OPEN ACCESS

Edited by:

Sophie Repp,

University of Cologne, Germany

Reviewed by:

Benjamin Spector,

École Normale Supérieure, France

Stefan Hinterwimmer,

University of Wuppertal, Germany

*Correspondence:

Satoshi Tomioka

stomioka@udel.edu

Specialty section: This article was submitted to

Language Sciences,

a section of the journal

Frontiers in Communication

Received: 22 March 2020 Accepted: 09 December 2020

Published: 14 January 2021

Citation:

Tomioka S (2021) Scalar Implicature, Hurford's Constraint, Contrastiveness and How They All Come Together. Front. Commun. 5:461553 doi: 10.3389/fcomm.2020.461553

\section{Scalar Implicature, Hurford's Constraint, Contrastiveness and How They All Come Together}

\author{
Satoshi Tomioka* \\ Department of Linguistics and Cognitive Science, University of Delaware, Newark, DE, United States
}

Disjunction with two scalar items, such as some or all of the books, has been regarded as evidence for the grammatical theory of scalar implicatures (e.g., Chierchia et al., 2012). Hurford's Constraint (Hurford, 1974) provides that disjuncts are banned from having an entailing relation, and to make such a disjunction comply with Hurford's Constraint, the meaning of some must be locally strengthened. Interestingly, however, the order of disjoined scalar items is not free, as noted by Singh (2008). The order in which a weaker scalar item comes first followed by its stronger scalar mate is better than the other order. I present an analysis of this ordering restriction based on the novel observation that the restriction is not only found in disjunction but in contrastive environments in general. I propose that contrasting a linguistic expression requires a "contrast antecedent," which must elicit a set of mutually exclusive alternatives that includes the meaning of the contrasted expression. It will be demonstrated how the mutual exclusivity requirement presents a principled explanation for the ordering asymmetry as well as Hurford's Constraint itself, which indicates that the root of the constraint is not in disjunction but in contrastiveness. One of the indispensable ingredients in the proposal is the grammatical/conventional generation of scalar implicatures, as the strengthened meaning must be the basis of alternatives. The paper also provides a speculative analysis of only, in which I suggest that the process of exhaustification in the grammatical theory of scalar implicatures should not be characterized as the implicit only, the semantic contributions of which are more different than commonly assumed.

Keywords: scalar implicature, disjunction, mutually exclusive, exhaustivity, contrastive

\section{HURFORD'S CONSTRAINT: WHAT IT IS AND WHY WE CARE}

Hurford (1974) noted that there is a felicity constraint that bans entailing disjuncts, as exemplified in (1).
(1) a. Anna lives in Seattle or in California.
b. \#Anna lives in Los Angeles or in California. 
Living in Los Angeles entails living in California, so they cannot be placed side by side in disjunction. No such ill effects are found in (1a), in which no entailment relation holds ${ }^{1}$.

Hurford further notes that $A$ or $B$ and $A$ and $B$ can be disjoined.

(2) Inmates may smoke or 1 drink, or 2 both. $=(20)$ in Hurford (1974, p. 410).

If both instances of or were to be interpreted as logical disjunction, this sentence is incorrectly predicted to be infelicitous because inmates may both smoke and drink entails inmates may smoke or drink. Hurford's conclusion is that the first instance $\left(=o r_{1}\right)$ is exclusive. In other words, it means, "Inmates may smoke or drink but not both."

As noticed by Gazdar (1979), however, this alleged strengthening is not limited to disjunction. A variety of "scalar mates" of the Horn Scales of Horn (1972) can be disjoined, as shown below.

(3) a. Erica visited France or Italy, or (both) France and Italy.

b. Anna ate some or all of the cookies.

c. Is Maria's academic record good or outstanding?

d. Is wearing a helmet recommended or required?

Logically, eating all of the cookies entails eating some of the cookies. The relations in ( $3 \mathrm{~cd}$ ) may be a little less straightforward, but one can still argue that entailment is involved there as well. Nonetheless, these sentences do not show the expected effects of Hurford's constraint violations. To make the disjunctions in (3) comply with Hurford's Constraint, it is necessary to strengthen the meaning of the scalar expressions that are in the entailed propositions, as indicated in (4).

(4) a. Erica visited France or Italy (but not both), or France and Italy.

b. Anna ate (only) some or all of the cookies.

c. Is Maria's academic record (just) good or outstanding?

d. Is wearing a helmet (only) recommended or required?

Crucially, the silent addition of those underlined expressions in the parentheses must take place before the meaning of the disjunctive structure is computed. This is the point that is at odds with the traditional Gricean approach to scalar implicatures. As a kind of conversational implicature, scalar implicature is standardly assumed to be generated after the calculation of the semantic meaning of a whole sentence is completed.

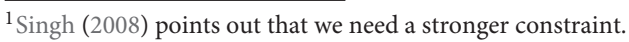

(i) a. Bertha drives a pick-up truck or an SUV.

b. \#Bertha drives a pick-up truck or a Ford.

There is no entailment relation between Bertha drives a pick-up truck and Bertha drives a Ford, which are merely consistent with each other. Singh strengthens Hurford's Constraint as: \# $X$ or $Y$ if $X$ and $Y$ are mutually consistent (Singh, 2008, p.252). For the purpose of the discussion in this current paper, however, we will not make reference to this stronger version of Hurford's Constraint.
Hurford's Constraint with disjoined scalar items, as well as other instances of embedded implicatures, has led to the emergence of the grammaticist or conventionalist approach to scalar implicature, represented by Chierchia (2006), Fox (2007), and Chierchia et al. $(2012)^{2}$.

(5) a. A scalar item generates scalar alternatives based on its meaning (using the Horn Scale).

b. The exhaustivity operator, $\mathrm{O}_{A L T}$, can be inserted at any sentential level.

c. This operator negates all of the non-weaker alternatives to the denotation of its complement, and the negated proposition is added to the denotation of its complement ${ }^{3}$. In other words, $\mathrm{O}_{A L T}(\mathrm{~S})=\mathrm{S}$ and all the propositions not entailed by $\mathrm{S}$ are false.

d. The addition of the negated proposition takes place at the level in which $\mathrm{O}_{A L T}$ appears.

It appears that what $\mathrm{O}_{A L T}$ does is not too far from the semantic effect of the adverb only, and $\mathrm{O}_{A L T}$ is often described as the silent version of it.Chierchia et al. (2012) suggest that the silent version of only is independently needed to derive exhaustive answers to questions. When someone utters, "Anna introduced [ERIC and FRED $]_{F}$ to Maria" as an answer to the question, "Who did Anna introduce to Maria?", it is naturally interpreted that Anna introduced Eric and Fred and no one else to Maria. According to Chierchia et al. (2012, p. 8), "What may be going on is that focus activates alternatives; active alternatives must be put to use and one option is via a covert occurrence of only. We may, then, assume that something very similar happens in the case of scalar alternatives."

The grammar of $\mathrm{O}_{A L T}$ presents a very straightforward representation of each sentence in (3) which does not violate Hurford's Constraint. Here is how (3b) complies with the constraint.

(6) a. $\left[\left[\mathrm{O}_{A L T}[\right.\right.$ Anna ate some (of the cookies) $]$ or $[$ (she ate) all of the cookies]].

b. $\left[\mathrm{O}_{A L T}\right.$ (Anna ate some of the cookies) $\leadsto$ Anna ate some of the cookies, and Anna did not eat all of the cookies.

c. $\left[\left[\mathrm{O}_{A L T}\right.\right.$ [Anna ate some (of the cookies)] or [(she ate) all of the cookies]] $\approx$ Anna ate only some of the cookies or all of the cookies.

\section{ORDERING ASYMMETRY}

While two scale-mate expressions can be disjoined, the order of the expressions is not free. Singh (2008) notes that a semantically stronger item cannot precede its weaker counterpart. I will place

\footnotetext{
${ }^{2}$ Of the grammaticist approach, I focus primarily on the proposal that makes use of a sentential exhaustivity operator, rather than other grammaticist analyses without such an operator (e.g., Levinson, 2000; Chierchia, 2004).

${ }^{3}$ Strictly speaking, the operator negates all the non-weaker alternatives that are "innocently excludable" (see Fox, 2007 for discussion). For the purpose of this paper, the simpler version is sufficient.
} 
\# in all of the examples below, but our judgments may fluctuate (and Fox and Spector, 2018 report that their corpus search produces some sizable number of exceptions, which they try to explain).

(7) a. \#Erica visited [(both) France and Italy] or [France or Italy].

b. \#Anna ate all of the cookies or some of the cookies.

c. \# Is Maria's academic record outstanding or good?

d. \# Is wearing a helmet required or recommended?

These examples become acceptable if only or just is added to the second disjuncts.

(8) a. Erica visited [(both) France and Italy] or just [France OR Italy].

b. Anna ate all of the cookies or only some of the cookies.

c. Is Maria's academic record outstanding or just good?

d. Is wearing a helmet required or only recommended?

The two analyses of this asymmetry, namely Singh (2008) and Fox and Spector (2018), both have the following characteristics.

(9) a. The contrast has its root in the way the silent exhaustive operator $\left(O_{A L T}\right)$ is licensed.

b. The licensing of $O_{A L T}$ is sensitive to structure (= disjunction) and its impact on the semantic environment.

c. In other words, $\left[\left(O_{A L T}\right) \mathrm{A}\right.$ or $\left.\mathrm{B}\right]$ is legitimate, but $[\mathrm{A}$ or $\left(O_{A L T}\right) \mathrm{B}$ ] is not.

Let us quickly review the gist of Fox and Spector's (2018) analysis. Compare the two disjunctive structures (10ab).

(10) a. $\left[\mathrm{O}_{A L T}[s\right.$ Anna ate some of the cookies $\left.]\right]$ or [s Anna ate [all] of them]

b. [s Anna ate [all] of the cookies] or [ $\mathrm{O}_{A L T}[S$ Anna ate [some] of them ]]

It should be noted that the presence of $\mathrm{O}_{A L T}$ has no effect on the context change potential of the whole sentences in (10). Whether $\mathrm{O}_{A L T}$ is attached or not, the assertion of those sentences leads to the elimination from the context set of all the possible worlds in which Anna did not eat any of the cookies. In this sense, the attachment of $\mathrm{O}_{A L T}$ is globally vacuous in both cases. At the point in which the attachment of $\mathrm{O}_{A L T}$ takes place in (10a), however, it is still unknown whether the presence of $\mathrm{O}_{A L T}$ in the first clause is vacuous or not. The first clause could have ended as an independent sentence, and in such a case, $\mathrm{O}_{A L T}$ is not vacuous. On the other hand, the presence of $\mathrm{O}_{A L T}$ in (10b) is doomed to be vacuous when the attachment takes place. When the first sentence is "Anna ate all the cookies" and it is followed by the disjunction "or," we need not wait till the meaning of the entire sentence is computed in order to know that $\mathrm{O}_{A L T}$ is vacuous. Thus, the presence of $\mathrm{O}_{A L T}$ is incrementally vacuous in (10b) but not in (10a). The incrementally vacuous use of $\mathrm{O}_{A L T}$ is not allowed, and as a consequence, the second disjunct of (10b) cannot furnish $\mathrm{O}_{A L T}$, which leads to a violation of Hurford's Constraint.

What I am about to propose for the ordering asymmetry is rather different from the previous analyses. The reason is clear and simple: I begin with an entirely different descriptive generalization of the ordering asymmetry. More concretely, I will show that the asymmetry is not limited to disjunctive structures, and that the relevant notion is contrastiveness, which includes disjunction but other constructions as well.

\section{ORDERING ASYMMETRY IN CONTRASTIVE ENVIRONMENTS}

Hurford's Constraint has been regarded as a constraint on disjunction, but it is not hard to find a similar pattern in other cases as well. Giorgio Magri (personal communication) pointed out, for instance, that the contrastive conjunction with but seems to impose the same restriction ${ }^{4}$.

(11) a. \#Adam was born in Paris but Bill in France.

b. \#Adam was born in France but Bill in Paris.

(12) a. \#Adam has a dog but Bill has a German Shepard.

b. \#Adam has a German Shepard but Bill has a dog.

Perhaps not surprisingly, contrasting scalar items works in the same way as well: two scalar items can be contrasted with each other even when one logically entails the other, provided that (i) the entailed item has its meaning strengthened, and (ii) the logically entailed item linearly precedes the entailing item ${ }^{5}$.

(13) a. Adam did some of the homework, but Bill did all of it.

b. Adam loves [Ann or Sue], but Bill loves [Ann and Sue].

c. Adam's academic record is good, but Bill's is exemplary.

(14) a. \#Adam did all of the homework but Bill did some of it.

b. \#Adam loves [Ann and Sue] but Bill loves [Ann or Sue].

c. \#Adam's academic record is exemplary, but Bill's is good.

It turns out that we do not have to look hard to find other contrastive environments where the same ordering asymmetry is observed. In all of the examples below, the order in which the logically entailing item precedes the entailed item is judged odder than the other order, and the degraded order is saved by the presence of an overt exhaustifying expression, such as only or just.

\footnotetext{
${ }^{4}$ I am grateful to Giorgio Magri for sharing data from his unpublished manuscript. ${ }^{5}$ Winterstein (2012) notes the same contrast [2012, (18) and (19)] but not in connection with Singh's (2008) paradigm of disjunction ordering.
} 
(15) a. Anna is more likely to have solved some of the problems than to have solved all of them.

b. \# Anna is more likely to have solved all of the problems than to have solved some of them.

c. Anna is more likely to have solved all of the problems than to have solved only some of them.

(16) a. Anna is more likely to become a good scholar than a brilliant one.

b. \# Anna is more likely to become a brilliant scholar than a good one.

c. Anna is more likely to become a brilliant scholar than just a good one.

The comparison between (17) and (18) reveals that the critical factor is the linear order, rather than the matrixsubordinate distinction.

(17) a. While/Although Anna read some of the books, Maria read all of them

b. \# While/Although Anna read all of the books, Maria read some of them

c. While/Although Anna read all of the books, Maria read only some of them

(18) a. Anna read some of the books while/although Maria read all of them.

b. \# Anna read all of the books while/although Maria read some of them.

c. Anna read all of the books while/although Maria read only some of them.

It is unclear whether all of these contrastive environments above have some structural commonality that can form the basis for an explanation of the asymmetry, but the pursuit in that direction is bound to be unsuccessful, as the same ordering asymmetry is found even in dialogs, as illustrated below ${ }^{6}$.

\footnotetext{
${ }^{6} \mathrm{An}$ anonymous reviewer questions the judgment on (20B) and (22B). It is important to note that the infelicity of $(20 \mathrm{~B})$ is based on the interpretation that $\mathrm{B}$ is reporting his belief that some but not all of Professor Smith's students are smart. However, the reviewer is right in that there is one way to make the mention of some acceptable in this context. The following is another hypothetical reply to A's statement.
}

(i) B": Wait, I know that some of them are, but are you sure that all of them are smart?

This reply with rise-fall-rise (RFR) prosody on some of them are leads to the "at least some" interpretation, rather than the "some but not all" interpretation. It is a feature of what is often described as "contrastive topic" (Büring, 1997, 2003; Lee, 2007; Tomioka, 2010), which generates a sense of unsettledness, uncertainty, or lack of commitment on the part of the speaker. In this particular example, the speaker indicates by using the contrastive topic prosody that she is not certain about the stronger alternative to "some of them are smart" (i.e., "all of them are"). The end result of this speaker's uncertainty is the "at least some" interpretation. Example (i) shows that, despite its name, contrastive topic is not regulated by our contrastiveness-based condition (the Contrast Antecedent Condition, Section 4.1.). One popular characterization of contrastive topic is that it embodies a particular strategy of answering a QUD (or a sub-question of a QUD). If so, its relation to the contrast antecedent (e.g., the corresponding scalar expression in the previous discourse) is much more indirect. The kind of contrastive dialog that
(19) A: Some of Professor Smith's students are smart.

B: I disagree! All of them are smart.

(20) A: All of Professor Smith's students are smart.

B: I disagree! \#Some of them are smart.

B': I disagree! Only some of them are smart.

(21) A: The food at that new restaurant was decent.

B: I disagree! I went there last week, and it was excellent.

(22) A: The food at that new restaurant was excellent.

B: I disagree! I went there last week, and \# it was decent.

B': I disagree! I went there last week, and it was only decent.

These dialog examples are particularly problematic for the previous analyses of the asymmetry. The infelicitous responses in (20B) and (22B) are independent sentences. When they are uttered in isolation, they are most likely to generate the relevant scalar implicatures as in (23).

a. Some of Professor Smith's students are smart. $\sim$ Some but not all of Professor Smith's students are smart.

b. It (the food at the new restaurant) was decent. $\sim$ It (the food at the new restaurant) was decent but not great.

If these readings are due to $\mathrm{O}_{A L T}$, it is not clear why its presence is blocked in the contrastive environments in (20) and (22).

Let us summarize what we have observed so far. The ordering asymmetry of Singh (2008) is found in contrastive environments beyond disjunction. When two scale-mates are contrasted, the better order is the one in which the semantically stronger one follows the weaker one. The second step is to identify the source of the asymmetry. The data examined above, especially the dialog cases, suggest that it is not about how to regulate the attachment of $\mathrm{O}_{A L T}$. The alternative analysis I explore is based on the following intuition.

(24) When two scale-mates are contrasted, the preceding one must be the right kind of "contrast antecedent" for the following one.

The idea is that the preceding scalar item must "set the stage" for a subsequent contrast. In the maligned all - some order, for instance, all fails to make a necessary preparation for the contrastive use of some. In what follows, I will spell out the condition for a good contrast antecedent.

\section{CONTRASTIVE FOCUS AND CONTRAST ANTECEDENT}

\subsection{Strengthening the Condition for Contrastive Focus}

The examples that we have examined so far highlight two crucial concepts: focus and contrast. The involvement of focus is obvious

(19) - (22) exemplify involves a more direct contrastive relation, such as denial or correction. 
because all the relevant scalar items in the examples above receive focal accents. Focus encompasses a vast range of empirical phenomena, and it does not seem to have a direct connection to Hurford's constraint and its ordering asymmetry.

(25) a. Anna is from [PARIS $]_{F}$. So, (it means) she is from $[\text { FRANCE }]_{F}$.

b. Currently, Anna is in $[\mathrm{FRANCE}]_{F}$. More concretely, she is in $[\text { PARIS }]_{F}$.

c. Anna's dream is to live in [PARIS $]_{F}$, but she might still be quite content if she lived in $[\mathrm{FRANCE}]_{F}$.

Being in Paris entails being in France, but such a relation does not seem to negatively affect the focalization pattern in (25), and the ordering does not matter, either. Rooth's (1992) theory of focus intends to capture the generality of focus. As briefly mentioned in connection with the notion of exhaustivity in Chierchia et al. (2012), focusing a linguistic expression elicits a set of alternative denotations of that expression. In Rooth's theory, this set denotation is used in a kind of anaphora resolution scheme: When a linguistic expression $\alpha$ is focused, there must be either (i) another linguistic expression $\beta$ whose denotation is a subset of the set of alternatives to the meaning of $\alpha$ or (ii) one whose meaning is an element of the set of alternatives to the meaning of $\alpha$. In (25a), for instance, "Anna is from [France $]_{F}$ " evokes a set of propositions of the form "Anna is from x." The previous sentence, "Anna is from Paris" can satisfy the condition since it can be an element of that set. It is clear that the ban on an entailment relation is not a part of Rooth's licensing condition, and that it should not be.

What focus provides is a set of alternatives, but this set is not constrained enough to derive the ban on entailment relations and the ordering asymmetry. This is where the second concept, contrast, comes into play. It is worth noting that the sentences in (25) do not have a strong sense of contrast comparable to the examples that we examined in the preceding section. The two sentences in (25a) could jointly answer the Question-underDiscussion, "What is Anna's nationality?", and (25c) can be uttered when someone wishes to know where Anna would like to live.

I admit that it is not always straightforward to give a precise characterization of what counts as "contrastive." There are definitely some expressions or constructions that generate a sense of contrast; disjunction, expressions such as but, on the other hand, instead, while, although, etc., and constructions like comparatives. In case of inter-speaker utterances, we may appeal to the rhetorical relation of contrast in the sense of Kehler (2002) and Asher and Lascarides (2003). In this paper, I primarily use example sentences with overt linguistic cues of contrast, such as disjunction or but, except for the few occasions when reference is made to dialog cases. In the dialog examples, the act of "correction" or "challenge" is used to elicit the necessary sense of contrast.

Intuitively speaking, it is fairly natural to suppose that, when two or more expressions are contrasted, their meanings are distinct from each other. For instance, pick-up truck and passenger car can be contrasted, but pick-up truck and vehicle cannot. It is also odd to contrast passenger car with $B M W$ where two properties overlap. The situation is reminiscent of Singh's (2008) stronger version of Hurford's Constraint based on mutual inconsistency (see footnote 1). I propose that contrastive focus demands a more specialized set of alternatives, namely a set of mutually exclusive alternatives, and that this stronger notion of alternatives is imposed on the scalar item that comes first ${ }^{7}$.

\section{(26) Contrast Antecedent Condition}

When $\alpha$ is contrastively focused, there must be $\beta$ that precedes $\alpha$ and generates $A L T_{\beta}$, a set of alternatives for $\beta$, such that

(i) it is a subset of the focus semantic value of $\beta$,

(ii) its members are mutually exclusive, and

(iii) it includes both the ordinary value of $\alpha$ and that of $\beta$.

I take the notion of mutual exclusiveness to be "mutual inconsistency" for propositions and "no mereological overlap" for entities. For other types, their mutual exclusivity is recursively defined: For any expressions $\alpha, \beta$ of type $<\mathrm{a}, \mathrm{b}>, \llbracket \alpha \rrbracket$ and $\llbracket \beta \rrbracket$ are mutually exclusive iff for all $\mathrm{x} \in \mathrm{D}_{a}, \llbracket \alpha \rrbracket(\mathrm{x})$ and $\llbracket \beta \rrbracket(\mathrm{x})$ are mutually exclusive. The term "mutual" should be understood to be strongly reciprocal. For a set to be mutually exclusive, any given pair of its members are mutually exclusive.

The idea of "contrast antecedent" in (26) embodies an unevenness that ultimately leads to the ordering asymmetry. However, the asymmetric aspect of contrast antecedent may be counter-intuitive because we often take it for granted that "contrast" is a symmetric relation. We often make a reciprocal statement like "A and B contrast with each other," and "A contrasts with B" seems equivalent to "B contrasts with A." The symmetry of contrast is also reflected in some linguistic analyses. In Rooth (1992), for instance, contrastively focused items can have a symmetric, inter-dependent relation with each other.

(27) An $[\text { American }]_{F}$ farmer was talking to a [Canadian $]_{F}$ farmer... Rooth [1992, p. 80 (11)]

The focus anaphor introduced with [American] $]_{F}$ takes [Canadian $_{F}$ as its antecedent, and vice versa. However, this symmetry of contrast is based on the notion of contrast as a state of affairs. What about the act of contrasting? First of all, language is a linear system, and therefore it cannot express a symmetry in its purest form. When two expressions are contrasted, one must linearly precede the other in the actual utterance since two expressions cannot be pronounced simultaneously. For this reason, we should not be too shocked to find linear order effects in seemingly symmetric linguistic environments. Take the contrastive use of but, for instance. The relevance of contrastiveness in the but conjunction is evident, and some have argued (e.g., Sæbø, 2003; Umbach, 2005) that contrast is the essential property that regulates the but conjunction. It has been noted (Blakemore and Carston, 2005; Winterstein, 2012 among many others), however, that

\footnotetext{
${ }^{7}$ Mutually exclusive sets of alternatives have been proposed for the universal free choice item, cualquiera, in Spanish by Menéndez-Benito (2010) and for focused adjectival modifiers by Wagner (2012).
} 
there are numerous instances of asymmetric but conjunctions where $p$ but $q$ and $q$ but $p$ are not equivalent. While Kehler (2002) argues that but marks either a discourse relation that is symmetric (a CONTRAST relation) or one that is asymmetric (a denial of expectation relation), Winterstein (2012) refutes this ambiguity-based characterization, showing that the distinction is not always straightforward. Particularly relevant is a case in which a contrast is undeniably present but the conjuncts are not symmetric.

(28) Where will you take your parents next year?

a. Well, FATHER would like somewhere NEARBY, but MOTHER really wants to go to PARIS.

b. Well, MOTHER really wants to go to PARIS, but FATHER would like somewhere NEARBY.

In both replies, father and nearby are contrasted with mother and Paris, respectively. The presence of contrast does not make the two but conjunctions equivalent, however. For instance, (28a) can be followed by a statement such as "So, Paris is a possibility." Such a continuation is rather unnatural in (28b). The precise explanation for this contrast is not too important for our current discussion. The lesson we learn from it is that the contrastive but can be asymmetric. In addition, a contrastive statement in a dialog presents an even clearer case of asymmetric contrast, as we have seen in the examples in (19) - (22). One can utter a contrastive sentence in connection to a preceding utterance by someone else, and in such a case, contrast is clearly asymmetric. A very short expression of contrast, such as a phrasal disjunction structure uttered by a single speaker, may feel very symmetric, but it is a special case, rather than a general case. In the scheme of (26), $A$ or $B$ can be regarded as symmetric (in the sense that it is identical to $B$ or $A$ ) when $A$ is a good contrast antecedent of $\mathrm{B}$ and $\mathrm{B}$ would be a good contrast antecedent of $\mathrm{A}$ if the order were reversed. Such a case "over-qualifies" with respect to the contrast antecedent condition, and it is special in that sense. I suggest that even in innocuously symmetric-looking contrastive environments, the order of presentation could matter, and that the condition on contrast antecedents captures the impact, one manifestation of which is the ordering asymmetry of scalar items.

\subsection{The Contrast Antecedent Condition at Work}

We are now ready to examine how the proposed conditions on contrast antecedent can account for the ordering asymmetry. Let us begin with the felicitous some - all order.

(29) [Anna ate $[\text { some }]_{F}$ of the cookies] or [Anna ate [all $]_{F}$ of the cookies]

[[some $]_{F} \rrbracket_{f}$ is a set of quantificational determiner meanings. While a focus value itself includes any expression of the same semantic type, the actual set of alternatives that are used for comparison (i.e., $A L T_{\text {some }}$ ) is much more constrained. Relatedly, the issue of scalar alternatives is a hotly debated topic (Horn 1989, Matsumoto 1995, Katzir 2007 among many others). The computation of a scalar implicature is assumed to use a set of scalar alternatives, and making a wrong choice in selecting alternatives can lead to an unattested implicature. There is also a question of how much the scalar alternatives for generating implicatures can influence the choice of focus alternatives. Fox and Katzir (2011) argue that the two sets of alternatives are one and the same, endorsing the structural-complexity-based account of Katzir $(2007)^{8}$. In analyzing scalar contrasts, I partially adopt Fox and Katzir's analysis in that the structural complexity can serve as a restriction on focus alternatives although its role is more limited than what Fox and Katzir envision. For the purpose of dealing with the ordering asymmetry, a relatively informal version of Katzir's constraint is sufficient: For a linguistic expression $\alpha$, focus alternatives must be structurally at most as complex as $\alpha^{9}$.

Turning back to $A L T_{\text {some }}$, it includes only those quantificational determiners the structures of which are at most as complex as some, such as every, no and probably non-logical lexical quantifiers like most, many, etc. Crucially, structurally complex quantifiers (e.g., almost all, many but not all) are not included. However, not all of the simplex quantifiers survive if $A L T_{\text {some }}$ is to be mutually exclusive. The mutually exclusive set of alternatives contains just two members, \{some, no\}. Since this set does not include the meaning of all, the contrast antecedent condition is still not met.

It is possible, however, to create a larger mutually exclusive set by strengthening the meaning of some to some but not all. In the scheme proposed by Chierchia et al. (2012), this can be achieved by adjoining $\mathrm{O}_{A L T}$ to the first disjunct. In this paper, I will combine $\mathrm{O}_{A L T}$ with the scalar item itself for convenience, and this choice should not be regarded as my endorsement of the lexicalist approach to implicatures (e.g., Levinson, 2000). We will revisit the sentential operator analysis of $\mathrm{O}_{A L T}$ in section 4.4. With the meaning of some strengthened, $A L T_{O[\text { some }]}$ becomes \{some but not all, no, all\}, where all is now added since it becomes mutually exclusive with the other two quantifiers ${ }^{10,11}$. Since $A L T_{O[\text { some }}$ includes the ordinary value of the second scalar item, the condition is now met. We should also be reminded that the strengthened meaning of some is often taken to be the default meaning (to the extent that some researchers, most notably Levinson (2000), argue that it is lexically encoded), which in turn means that the inclusion of the meaning of all in the mutually exclusive set is done fairly easily.

\footnotetext{
${ }^{8}$ However, Fox and Katzir's (2011) discussion primarily concentrates on association-with-focus cases.

${ }^{9}$ Slightly more formally: for any pair of two structures, S, S, S' is at most as complex as $S$ in a context $C$ if $S^{\prime}$ can be derived from $S$ by successive replacements of subconstituents of $\mathrm{S}$ with elements of the substitution source for $\mathrm{S}$ in $\mathrm{C}$ [Fox and Katzir, 2011, (34)].

${ }^{10} \mathrm{I}$ assume the presuppositional reading of all where its argument cannot be the empty set. This assumption is conventionally adopted in the studies of scalar implicatures.

${ }^{11}$ Since the structural complexity of some increased to $\left[\mathrm{O}_{A L T}\right.$ some], $\mathrm{O}_{A L T}$ can in principle contain other quantifiers of the form $\left[\mathrm{O}_{A L T} Q\right]$ where $Q$ is a simplex quantificational determiner. However, the other candidates, such as $\left[\mathrm{O}_{A L T}\right.$ most $]$, are not mutually exclusive with $\left[\mathrm{O}_{A L T}\right.$ some $]$. Moreover, there is an additional constraint on the set based on relevance of alternatives, as we will discuss later in this section.
} 
On the other hand, the all - some order cannot satisfy the condition, and the following steps illustrate how it fails. The intended reading is the interpretation which would not violate Hurford's Constraint, and the meaning is syntactically represented as in (30). Unlike the analyses of Singh (2008) and Fox and Spector (2018), the current proposal does not prohibit the strengthening in the second disjunct.

(30) \# Anna ate $[\text { all }]_{F}$ of the cookies or Anna ate $\left[\mathrm{O}_{A L T} \text { some }\right]_{F}$ of the cookies.

The focus value of $\llbracket[a l l]_{F} \llbracket \llbracket \rrbracket_{f}$ is a set of quantificational determiner meanings, and $A L T_{\text {all }}$ contains only those quantifiers whose structural complexities do not exceed that of all. Among those, only a couple of simplex determiners are inconsistent with all: no and possibly few. Importantly, the mutually exclusive $A L T_{\text {all }}$ does not include either the logical meaning of some or the strengthened meaning of some. The former is not mutually exclusive with all, and the latter involves more structure with the additional ingredient, namely $\mathrm{O}_{A L T}$. In contrast with the previous case with some, the mutually exclusive set cannot be expanded any further. Strengthening the meaning of all is not possible, as it is the strongest among the quantifiers that have entailment relations with all. The failure of strengthening is the cause of the unchanged $A L T_{\text {all }}$.

There is more than one way to cash out this intuition. The critical difference depends on the assumption on what primarily guides the expansion of $\mathrm{ALT}_{\alpha}$, whether it is the syntactic structure of $\alpha$ or the semantic denotation of $\alpha$. If the structure is the key factor, then, the structure $\left[\mathrm{O}_{A L T}\right.$ all $]$ must be blocked. Otherwise, the inclusion of other quantifiers of the form $\left[\mathrm{O}_{A L T}\right.$ $Q]$, such as $\left[\mathrm{O}_{A L T}\right.$ some], would be allowed, and we would incorrectly predict (30) to be legitimate. The ban on semantically vacuous attachment of $\mathrm{O}_{A L T}$ can be facilitated by following Fox's (2000) notion of derivational economy ${ }^{12}$. If the primary force of expansion of $A L T_{\alpha}$ is the semantic denotation of $\alpha$, on the other hand, no special reference to the syntax of $\mathrm{O}_{A L T}$ is needed. Since the ordinary semantic value of $\left[\mathrm{O}_{A L T}\right.$ all $]$ is identical to that of all, $A L T_{\text {all }}$ is unchanged. Therefore, the set cannot include the ordinary value of $\left[\mathrm{O}_{A L T}\right.$ some $]$, and all remains inadequate as a contrast antecedent for $\left[\mathrm{O}_{A L T} \text { some }\right]^{13}$.

\footnotetext{
${ }^{12}$ As mentioned in connection with example (10), the attachment of $\mathrm{O}_{A L T}$ in the acceptable structure, $\left[\mathrm{O}_{A L T}\right.$ some $]$... or all ... ], is globally vacuous although it is meaningful within the first disjunct. It must be the case, therefore, that the ban on semantically vacuous attachment of $\mathrm{O}_{A L T}$ is computed locally. I am grateful to an anonymous reviewer for drawing my attention to this point.

${ }^{13}$ In the original formulation of Katzir's (2007) account, a structurally more complex alternative is added when it is subsequently mentioned explicitly. The main motivation for such a move is based on Matsumoto's (1995) example.
}

(i) It was warm yesterday, and it is a little bit more than warm today (Matsumoto, 1995, ex. 39, p. 44)

The first sentence seems to implicate that it was not a little more than warm yesterday, and to generate the implicature, "a little bit more than warm" must be a (stronger) scalar alternative that must be considered for "warm" even though it is obviously more complex than "warm." This mechanism may be needed for the computation of implicatures, but it is incompatible with the current proposal, for which subsequent mention of scalar alternatives itself is the subject of regulation.
To tell the two approaches apart, we examine a case of a stronger but not the strongest scalar item as a contrast antecedent. Consider (31), which patterns together with the infelicitous all-some order ${ }^{14}$.

(31) a. \#Anna ate most of the cookies, or Anna ate some of the cookies.

b. Anna ate $\left[\mathrm{O}_{A L T}\right.$ most $]$ of the cookies, or Anna ate $\left[\mathrm{O}_{A L T}\right.$ some $]$ of the cookies.

Unlike all, the attachment of $\mathrm{O}_{A L T}$ to most is not vacuous. Therefore, the structure will not be ruled out by the relevant Economy consideration. Nonetheless, it cannot serve as a good contrast antecedent for some, or $\left[\mathrm{O}_{A L T}\right.$ some $]$ to be more precise. If the structure $\left[\mathrm{O}_{A L T}\right.$ most] would license the inclusion of all quantifiers of the form of $\left[\mathrm{O}_{A L T} Q\right]$, provided that they are mutually exclusive with $\left[\mathrm{O}_{A L T}\right.$ most $],(31 \mathrm{a})$ is predicted to be well-formed, contrary to fact. We can conclude from (31) that Katzir's structural-complexity-based condition does not determine the membership of alternatives although it can serve as a restriction on it. In other words, the alternatives in $\mathrm{ALT}_{\alpha}$ must be structurally as complex as or less complex than $\alpha$, but not all candidates that satisfy that structural requirement can be in $\mathrm{ALT}_{\alpha}$ even if the mutual exclusiveness condition is met.

When $\alpha$ is strengthened via $\mathrm{O}_{A L T}$, the ordinary semantic value of $\left[\mathrm{O}_{A L T} \alpha\right]$ drives the expansion of $\mathrm{ALT}_{O[\alpha]}$. More concretely, we suggest that the exclusion of stronger alternatives makes those very alternatives highly relevant and be included in $\operatorname{ALT}_{O[\alpha]}$ :

(32) a. When $\left[\mathrm{O}_{A L T} \alpha\right]$ is not vacuous, there is $\beta$, a stronger alternative to $\alpha$, that is to be negated by $\left[\mathrm{O}_{A L T} \alpha\right]$.

b. This process makes the issue of whether $\beta$ or not $\beta$ highly relevant, and $\beta$ is added to the mutually exclusive $A L T_{\alpha}$.

In example (31), the relevant stronger alternative is all. Thus, $A L T_{\text {most }}$ now includes all but not some (or more precisely some but not all/most). Therefore, (31) remains infelicitous. With all, there is no stronger alternative to be excluded, and as a consequence, ALT $_{\text {all }}$ does not expand. While we may still wish to ban the semantically vacuous attachment of $O_{A L T}$ for an independent reason, such a prohibition is not necessary to account for the ordering asymmetry.

To sum up, the condition on contrast antecedents can provide a straightforward account for the ordering asymmetry. The examination has so far focused on the some - all pair in disjunction, but the analysis is generalizable to other scalar items in contrastive environments in general.

(33) Successful Weak-Strong Order: For a pair of scalar items $\alpha, \beta$, where $\alpha$ is weaker/less informative than $\beta$ and $\alpha$ linearly precedes $\beta$,

a. The mutually exclusive set of alternatives for $\llbracket \alpha \rrbracket$ cannot include $\llbracket \beta \rrbracket$ because they are not mutually exclusive.

\footnotetext{
${ }^{14} \mathrm{I}$ am grateful to an anonymous reviewer for pointing out this example to me.
} 
b. However, $\alpha$ can be strengthened via $\left[O_{A L T}[\alpha]\right]$, and $\left[O_{A L T}[\alpha]\right]$ now excludes $\llbracket \beta \rrbracket$.

c. This exclusion process makes $\llbracket \beta \rrbracket$ highly relevant, and it is now included in the mutually exclusive set of alternatives for $\llbracket\left[O_{A L T}[\alpha]\right] \rrbracket$.

d. Therefore, the order of $\alpha-\beta$ in contrastive environments is felicitous, as $\alpha$, or more strictly speaking, $\left[O_{A L T}[\alpha]\right]$ is a good contrast antecedent.

(34) Unsuccessful Strong-Weak Order: For a pair of scalar items $\alpha, \beta$, where $\alpha$ is stronger/more informative than $\beta$ and $\alpha$ linearly precedes $\beta$,

a. The mutually exclusive set of alternatives for $\llbracket \alpha \rrbracket$ can include neither $\llbracket \beta \rrbracket$ nor $\llbracket\left[O_{A L T}[\beta]\right] \rrbracket$. The former is not mutually exclusive with $\llbracket \alpha \rrbracket$, and the latter is structurally more complex than $\llbracket \alpha \rrbracket$.

b. Since $\alpha$ is the stronger scalar item, the strengthening via $\left[O_{A L T}[\alpha]\right]$ does not exclude $\llbracket \beta \rrbracket$. Thus, the mutually exclusive set of alternatives still cannot contain $\llbracket \beta \rrbracket$ or $\llbracket\left[O_{A L T}[\beta]\right] \rrbracket$.

c. Therefore, the order of $\alpha-\beta$ in contrastive environments is infelicitous, as $\alpha$ is not a good contrast antecedent for $\beta$ or $\left[O_{A L T}[\beta]\right]$.

The critical difference between (33) and (34) is whether a contrast antecedent can be strengthened in such a way that its contrast mate is regarded highly relevant. When the weaker item is strengthened, the stronger item becomes highly relevant and is included in the set of mutually exclusive alternatives while the stronger item does not undergo a comparable process. This difference leads to the ordering asymmetry. It is also highly important to note that the proposed explanation requires the ordinary value of a contrasted scalar item to be strengthened, as in (33b). In the disjunction examples that we examined in this section, for instance, the strengthening must take place locally within the first disjunct. The grammatical approach to scalar implicatures makes an easy choice for this process. While the current proposal departs from Singh's (2008) and Fox and Spector's (2018) grammar-based accounts of the ordering asymmetry, it still endorses the grammaticist's approach to scalar implicatures, as these previous analyses do.

\subsection{Beyond the Basic Asymmetry}

We have so far analyzed clear cases of Singh's ordering asymmetry in broader contrastive environments. However, there are several more complicated and subtle issues that go beyond the basic pattern, and this section examines whether these challenges are met by the proposed account.

First of all, observe that polar opposite contrasts are felicitous in either order. This is predicted as either scalar item can have the other as a mutually exclusive alternative.

a. Anna ate all of the cookies or none of the cookies.

b. Anna ate none of the cookies or all of the cookies.

a. Anna is an excellent cook or a bad cook

\section{b. Anna is a bad book or an excellent cook.}

Interestingly, the order of strong - weak becomes acceptable if the polar opposite of the strong item is also mentioned explicitly as an alternative, as shown below.

(37) a. It is not known whether Anna ate all, (or) some or none of the cookies.

b. (Of course,) Anna ate all, (or) some or none of the cookies. We just don't know which is true.

a. We are debating whether Anna is an excellent cook, a good cook or a bad cook.

b. This spa has many choices. A hot bath, a warm bath, and a cold bath. A dry sauna and a steam room, too. Enjoy!

In these examples, the weaker items in the middle are strengthened: some (but not all) in (37), good (but not excellent) in (38a) and warm (but not hot) in (38b). Intuitively speaking, the mention of polar opposite alternatives can create a "multiplechoice-survey" like context where middle categories are carved out as independent categories. A theoretical explanation of this "carving out the middle" effect is not straightforward. If the middle scalar items are strengthened with $O_{A L T}$ to be mutually exclusive with the stronger items, the question is how they are legitimate alternatives even though they are more structurally complex alternatives. It is noteworthy, in connection to this puzzle, that an overtly strengthened expression can seem to be an alternative in a similar context. Consider excellent and very good, for instance. Clearly, very good should not be a good focus alternative to excellent, as the former is more complex with an overt intensifier. As expected, the disjunctive structure, excellent or very good, sounds quite infelicitous. The structure improves dramatically, however, when it is embedded in a list like excellent, very good, good, satisfactory, or bad, and very good in this context is indeed interpreted as 'very good but not excellent'. At this point, the explanation remains rather descriptive, but the effects are robust.

The improvement by polar contrast is the strongest if the relevant polar alternatives are mentioned in a "list-like" fashion, as in the examples above. The following are examples where the polar alternatives are mentioned separately from the relevant disjunctions.

(39) a. ?'We know it is impossible that Anna ate none of the cookies, as she simply cannot resist cookies. The question is whether she ate all of them or some of them.

b. 'We all agree that Anna is definitely not a bad student. We are still debating, however, whether Anna is an excellent student or a good student.

While they do not sound as natural as (37) and (38), many speakers find them more or less acceptable. Does the presence of a polar alternative need to be overt, or does it suffice if the utterance context clearly indicates its existence? Here are some test cases. 
(40) Context: Professor Smith is telling her students how they performed in the recent exam in very general terms. Not surprisingly, no students got zero points. Also not surprisingly, not all students got all the answers right. And one of the students is saying to himself:

?(?)I wonder if I got all the answers right or some of them right..

(41) Two professors are evaluating a qualifying paper by one of their graduate students. They have already agreed that the paper should pass. They are now debating whether the paper should get "pass" or "pass with distinction," the higher honor. One of them says:

?(?) The question is whether it is an excellent paper or a good paper.

The judgment of these examples is delicate. They are perhaps a little odder than (39), and the addition of only or just to the second disjuncts makes them more natural. Nonetheless, the sentences sound much better in these contexts than when they are presented without any specific background information. In (40), the possibility of someone getting no answers right was considered (and eliminated). (41) indicates that the question of whether the paper is a bad paper was relevant prior the utterance context. Contextual information of this kind still encourages the hearer to maintain no and bad as alternatives in the context, and this appears to lead to the inclusion of the strengthened version of some and good in the set of mutually exclusive alternatives.

The gradual decline of improvement from (37)/(38) to (39) to $(40) /(41)$ is very indicative of a more layered and nuanced situation than what the categorical labeling of felicity implies. The generalization is that the level of salience of polar alternatives corresponds to the degree of ease of making the middle ground alternative available. When one makes a list of choices in the form of disjunction or conjunction, all the to-be-mentioned alternatives are highly salient at the time of utterance. Without overt mention, the salience of the relevant polar alternative decreases, but the context can still sustain it to a certain level so that one may find a way to access the middle ground.

The discussion leading up to this point raises a new question: In general, how bad or how infelicitous is the "strong-weak" order of scalar items in the first place? So far I have followed the practice adopted in the previous studies on this topic and used categorical labels. A sentence in question is either felicitous or infelicitous (marked by \#). There is definitely something stable, namely the preference of the "weak-strong" order in contrastive environments. However, the overall judgment patterns of the native speakers that I have consulted for this project were not categorical. The supposedly unacceptable "strong - weak" order is awkward but not hopelessly infelicitous, and the intended contrast is somehow achievable with some effort. Fox and Spector's (2018) corpus study is consistent with this overall judgment pattern. For instance, they found in the Corpus of Contemporary American English (http://corpus.byu.edu/coca/) 53 instances of all - some, as opposed to 396 of some - all, in disjunction. While these statistics confirm the strong preference of the "weak - strong" order of two scalar items in disjunction, they also suggest that the other less preferred order can occur with some regularity. Our findings regarding the role of polar opposite alternatives suggest that the relatively mild infelicity of the "strong-weak" order of scalar items can be due to our willingness to imagine the weaker item to be the relevant middle ground even when there is no clear indication of the presence of the polar opposite to the stronger item. It is definitely a kind of process that requires some effort, contrasting sharply with the "weak - strong" order, which generates a suitable set of alternatives with ease by appealing to $O_{A L T}$, a readily available procedure.

While the ordering asymmetry is generally more gradable than categorical, there is an interesting case in which the ill-effects of the "strong - weak order" are much more pronounced, to the extent that the judgment seems categorical. It is a case of the contrast between "A" and "A and B." The two paradigms, one in disjunction and the other in a but-conjunction, are shown below.

(42) a. Andy insulted [ANNA] or [Anna AND her SISTER].

b. \# Andy insulted [Anna AND her SISTER] or [ANNA].

c. Andy insulted [Anna AND her SISTER] or only ANNA.

(43) a. ANDY insulted ANNA, but BILLY insulted Anna AND her SISTER.

b. \#BILLY insulted ANNA and her SISTER, but ANDY insulted ANNA.

c. BILLY insulted ANNA and her SISTER, but ANDY insulted only ANNA.

The infelicity of (42b) and (43b) is very strong. These cases are judged far worse than the all - some or the other scalar items that we have examined so far. In order to generate the intended interpretations [ $=$ the interpretations comparable to (42a) and (43a)], it is necessary to add only or just. The question is why the effects are so strong in these examples. Additionally, the felicity of (42a) and (43a) presents an interesting puzzle. In these examples, the proper name Anna is strengthened to [ $O_{A L T}$ Anna] so that it means "only Anna." Since (42a) and (43a) are perfectly acceptable, it indicates, under the current proposal, that the strengthened Anna can be a contrast antecedent for Anna and her sister, which is, at least superficially, more structurally complex. Therefore, $A L T_{O[A n n a]}$ should not include the meaning of Anna and her sister, which is an alternative to $A L T_{O[A n n a]}$ under Katzir's definition of alternatives. One possible solution is to adopt Sauerland's (2004) artificial binary conjunctions $L$ and $R$ involved in these cases. With these conjunctions, an atomic formula can be regarded as structurally parallel to conjunction and disjunction. Semantically, $L$ returns the semantic value of what comes to its left: for any $\phi, \psi, \llbracket \phi L \psi \rrbracket=\llbracket \phi \rrbracket . R$ is the mirror image of $L: \llbracket \phi R \psi \rrbracket=\llbracket \psi \rrbracket$. Sauerland's conjunctors make the proper name Anna as structurally complex as one with the conjoined counterpart, and the inclusion of Anna and her sister in the set of alternatives becomes possible. There may be other 
solutions with or without modifying Katzir's concept of structural complexity ${ }^{15}$. I assume that the challenge can be overcome and will focus on the issue of the strong infelicity of (42b) and (43b).

I suggest that this stronger ill-effect coincides with the failure of the "carving out the middle" strategy. As the following examples show, adding the polar opposite of "(both) A and B," namely "neither A nor B," helps to strengthen "(either) A or B" to "(either) A or B but not both," but it still fails to strengthen " $\mathrm{A}$ " to "only A" or "A but not B."

a. Andy insulted [(both) Anna and her sister], (or) either one of them, or neither of them. I don't know exactly what happened.

b. \# Andy insulted [(both) Anna and her sister], (or) Anna, (or) her sister, or neither of them. I don't know exactly what happened.

c. Andy insulted [(both) Anna and her sister], (or) only Anna, (or) only her sister, or neither of them. I don't know exactly what happened.

In (44b), neither " $A$ " alone nor " $B$ " alone can independently be carved out and strengthened. If the milder infelicity of other scalar pairs is derived from the "carving out the middle role" of a polar opposite alternative, as the current proposal hypothesizes, the strong infelicity of (42b) and (43b) is correctly predicted. As for why each conjunct fails to be strengthened even in the "list-like" context with the polar alternatives, I suggest that it is due to the non-unique nature of the scales involved with them. For all the other scalar contrasts, there are unique scales: "all - some - no," "excellent - good - bad," "hot - warm - cold," for example ${ }^{16}$. For conjunction, however, both conjuncts, or in Sauerland's (2004) $L$ and $R$, cannot be placed on the same scale. Instead, there are two independent scales: "A and B - A - either A or B - neither A nor B" and "A and B - B - either A or B - neither A nor B." This parallel existence of two independent scales makes it not possible for " $A$ " or " $B$ " to be strengthened. If we eliminate $\mathrm{A} / \mathrm{B}$ from the two scales, on the other hand, they merge into one scale: "A and B - either A or B - neither A nor B." Thus, either $A$ or $B$ can be made into an independent middle category, as the acceptable example (44c) shows.

Another question that naturally arises at this point is: does the addition of a non-polar-opposite alternative also help? One example related to this question is discussed in Fox and Spector (2018). They claim that previous mention of most makes the all some order acceptable ${ }^{17}$.

\footnotetext{
${ }^{15}$ In this instance, the structural complexity may not be playing any role. According to the reasoning behind the expansion of alternatives in (32), $\left[O_{A L T}\right.$ Anna] excludes (both) Anna and her sister, which makes (both) Anna and her sister highly relevant and be included in $\operatorname{ALT}_{O[A n n a]}$. The felicity of (43a) suggests that this step is good enough, making the restriction based on structural complexity irrelevant.

${ }^{16} \mathrm{I}$ am simplifying the discussion by ignoring monotonicity. In other words, I am putting positive scales (e.g., "excellent - good") and negative scales ("bad terrible") together. While monotonicity may play an important role in generating implicatures [as argued by Horn (1989) and Matsumoto (1995)], I assume it is not relevant for focus alternatives.

${ }^{17}$ For this improvement effect, Fox and Spector (2018) use the notion of "distant entailing disjunction." Since their account assumes the asymmetry to be confined
}

(45) A: Did John do most of the homework?

B: No. He did all of it or some of it. = Fox and Spector [2018, (47)]

While this example is presented as an acceptable case of the "all - some" order, I have not had much success in replicating as clear a judgment as Fox and Spector report. Some of my consultants felt that the sentence improves somewhat, but others didn't find it noticeably better. Instead of contradicting Fox and Spector's report, I assume that (45) manifests improvement which is nonetheless weaker and more variable than Fox and Spector's portrayal $^{18}$. The first step toward a possible analysis is to treat A's question, "did John do most of the homework?", as a more specified version of the general question, "How much of the homework did John do?", which we may regard as Questionunder-Discussion (QUD) in (45) (cf. Roberts, 1996) ${ }^{19}$. From then on, the conversation in (45) proceeds as follows.

a. B's "no" response means that (B believes/knows that) it is not the case that John did most of the homework.

b. However, B's "no" response in (45) must be the negation of the strengthened meaning of most, namely "most but not all," because the negation of the unstrengthened most would be contradictory with B's subsequent statement, he did all or some of it.

c. Finally, B follows up and addresses the QUD, "how much of the homework did John do?", by offering a positive answer to one of the two other related polar questions, "Did John do all of the homework?", "Did John do some of the homework?".

The process in (46) creates a context in which there are several polar questions out of the QUD. They in turn can lead to a multiple-choice-answer scenario with respect to the QUD: all, most, some and no. As we discussed above, a multiple-choice context encourages the choices to be mutually exclusive, and the

within disjunctive structure, it will not reviewed in this paper. See section 5.2.2.1 of Fox and Spector (2018) for more discussion.

${ }^{18}$ Fox and Spector (2018) acknowledge that some of the judgments they report are delicate. "As we develop our proposal we will be presenting a variety of very detailed predictions, some of which will involve rather subtle contrasts in acceptability judgments. We are not always as confident about these judgments as we would like to be. Nevertheless we think that stating the predictions explicitly would be useful in understanding the nature of our proposal. Within the current proposal, the effect can be derived via the following steps" (Fox and Spector, 2018, p. 7). (45) seems to be one such instance involving a subtle judgment.

${ }^{19}$ The concept of "more specified question" is not identical to the notion of subquestion discussed in Roberts (1996), Beck and Sharvit (2002), and Büring (2003), and others. An exhaustive answer to a subquestion of Q is a partial answer to Q. (i) is an example of the subquestion relation, in which the last two questions are subquestions of the first.

(i) Who recommended who? Who did Maria recommend? And who did Anna recommend?

A "more specified question" of $\mathrm{Q}$ is a polar question made out of one possible answer to $\mathrm{Q}$, as illustrated in (ii). A positive answer to a more specified question answers the general question, but a negative answer does not.

(ii) How much was the ticket to the concert? Was it $\$ 100$ ? $\$ 150$ ? 
ordering asymmetry of the scalar items often disappears. In Fox and Spector's example (45), the presence of the relevant QUD is only implied, but it can be made explicit, as in (47). Its addition seems to enhance the improvement effect.

(47) A: How much of the homework did John do? Did he do most of it?

B: No. He did all of it or some of it.

This kind of gradient improvement is expected, as it patterns with the variable improvement effects that we saw above in connection with other multiple-choice environments.

To summarize our discussion in this subsection, we have examined several cases in which the allegedly infelicitous "strong - weak" order becomes acceptable or is at least tolerated. The presence of a polar-opposite alternative is playing a pivotal role in increasing the felicity of this disadvantaged order. The salience of a relevant polar alternative can be raised in a variety of ways, and its impact on the ordering asymmetry surfaces as the gradable/variable judgment of acceptability.

\subsection{Fine-Tuning the Contrast Antecedent Condition}

So far, the target of the Contrast Antecedent Condition has been focused scalar items themselves. The key ingredient is that a good antecedent in a scalar contrast has the potential to be strengthened, and the way I have been describing the processes seems to imply that the required strengthening mechanism is lexical. While the phenomena examined in this paper are certainly compatible with the lexicalist version of the grammaticist approach, that is not the only option ${ }^{20}$. As reviewed earlier, the grammaticist approach of Chierchia et al. (2012), for instance, employs a clausal operator to achieve the required exhaustification. It is worth considering how the proposed condition can accommodate the sentential operator $\mathrm{O}_{A L T}$.

(48) Contrast Antecedent Condition': Alternative to (26) For any phrase $\alpha$ and $\alpha$ ' such that $\alpha$ is dominated by $\alpha$, when $\alpha$ is contrastively focused, there must be $\beta$ which precedes $\alpha$ and is dominated by $\beta$ ' which generates $A L T_{\beta^{\prime}}$, a set of alternatives for $\beta$, such that

(i) it is a subset of the focus semantic value of $\beta$,

(ii) its members are mutually exclusive, and

\footnotetext{
${ }^{20}$ The data in this paper do not distinguish the approach that encodes the strengthened meaning at the lexical level (e.g., Levinson, 2000; Chierchia, 2004) from the clausal operator approach. As a matter of fact, a version of the lexical approach is put forth for contrasted scalar items by Geurts (2010, Chapter 8), who is a committed advocate of the globalist approach. He argues that a contrasted scalar item undergoes lexical narrowing/strengthening, which would be compatible with the current proposal. The choice between the lexicalist or the clausal operator approaches must come from facts other than the ones considered here. Sauerland $(2012,2014)$ presents a critical review of the lexicalist appraoch based on the observation that there are numerous instances of intermediate implicatures that the lexicalist approach predicts to be impossible. Tomioka (2019) endorses Sauerland's conclusion by closely examining Geurts' hypothesis with special attention to the scope properties of contrasted scalar quantifiers. It is shown that the scope of a scalar implicature does not match that of the relevant scalar item, contrary to what Geurts' analysis predicts. All in all, the lexicalist approach faces more empirical challenges than the clausal operator approach.
}

(iii) it includes both the ordinary value of $\beta^{\text {' and that }}$ of $\alpha^{\prime}$.

Here is a case study of this definition.

a. $\left[\mathrm{O}_{A L T}\left[\right.\right.$ Anna ate $[\text { some }]_{F}$ of the cookies]] or [Anna ate $[\text { all }]_{F}$ of the cookies]]

b. $\alpha=$ all

$\beta=$ some

$\alpha^{\prime}=$ Anna ate all of the cookies

$\beta^{\prime}=O_{A L T}$ [Anna ate some of the cookies]

c. $\llbracket \alpha^{\prime} \rrbracket_{o}=$ Anna ate all of the cookies.

$A L T_{\beta^{\prime}}=\{$ Anna ate some but not all of the cookies, Anna ate all of the cookies, Anna ate none of the cookies\}

d. Therefore, $\llbracket \alpha^{\prime} \rrbracket_{o} \in A L T_{\beta^{\prime}}$, and the condition is met.

The current version of the Contrast Antecedent Condition needs further fine-tuning in order to accommodate inter-speaker contrasts. In a dialog, a speaker can make a contrastive statement in relation to what has been uttered by another conversation partner. For this partner, there is no notion of "planning ahead" or "forecasting" for what kind of contrastive statement may follow her statement. When a speaker utters a contrastive statement with the linguistic expression $\alpha$ being focused, the contrast antecedent of $\alpha$ may or may not be focused. The following conversations exemplify this scenario. There are two noteworthy points in these examples: (i) it is possible to contrast a scalar item even when the corresponding scalar item in the previous sentence is not focused, and (ii) the ordering asymmetry is still present.

(50) A: What are the students in your department working on these days?

B: Let's see, some of ANNA's students are working on IMPLICATURE, and...

C: Not true! ALL of her students are working on implicature.

(51) A: What are the students in your department working on these days?

B: Let's see, all of ANNA's students are working on IMPLICATURE, and...

C: Not true! \#(Only) SOME of her students are working on implicature.

(52) A: Which students in your program do you think highly of?

B: Let's see, ANNA is a good student, and so is BERTHA, and ...

C: Wait, Bertha is a BRILLIANT student. She should not be mentioned in the same sentence with Anna.

(53) A: Which students in your program do you think highly of?

B: Let's see, ANNA is a brilliant student, and so is BERTHA, and ...

C: Wait, Bertha is \#(just) a GOOD student. She should not be mentioned in the same sentence with Anna. 
In light of these examples, the condition must be modified. First, we need to define the concept of potential focus values.

(54) A potential focus value of a linguistic expression $\gamma$ is the focus value of $\gamma^{\prime}$, which is identical to $\gamma$ except for the location of F-marking.

We add this concept to (48).

(55) Contrast Antecedent Condition": Modified version of (48)

For any phrase $\alpha$ and $\alpha^{\prime}$ such that $\alpha$ is dominated by $\alpha$, when $\alpha$ is contrastively focused, there must be $\beta$ which precedes $\alpha$ and is dominated by $\beta$ ' which generates $A L T_{\beta^{\prime}}$, a set of alternatives for $\beta$, such that

(i) it is a subset of the actual or a potential focus semantic value of $\beta$,

(ii) its members are mutually exclusive, and

(iii) it includes both the ordinary value of $\beta^{\prime}$ and that of $\alpha^{\prime}$.

Consider (50), for example. The constituent that corresponds to the contrast antecedent is some of Anna's students are working on implicature, where the main foci fall on Anna's and implicature. Thus, the actual focus value of this sentence is a set of propositions of the form "some of X's students are working

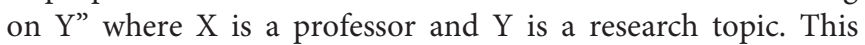
would not be a good basis of the right contrast antecedent for the subsequent contrastive statement. There is a potential focus value of this sentence where the main focus shifts to some. Then, that hypothetical focus value is a proposition of the form " $Q$ of Anna's students are working on implicatures," and after some is strengthened via $\mathrm{O}_{A L T}$, it becomes a mutually exclusive set, namely some but not all of Anna's students are working on implicatures, all of Anna's students are working on implicatures, none of Anna's students are working on implicatures\}, which satisfies the condition.

\subsection{No Asymmetry in Non-contrastive Environments}

The current proposal predicts that the "stronger - weaker" order of scalar items causes no ill effects when the scalar items are not contrasted. This prediction is borne out.

(56) Context: Your colleague is directing a study abroad program to Japan, and you are worried that the students may not have sufficient international experience to do well in the program. Your colleague says she is not worried, saying...

All the students have been to Europe. Some of them have actually been to Japan before.

\section{How was your hotel in Paris?}

$\mathrm{Oh}$, the room was absolutely beautiful, the service was impeccable, and the location was good. So, we were very happy.
These examples are natural with the potentially problematic order of scalar items. The difference here is that they are not contrasted with each other. In both cases, the sentences collectively give an answer to the QUDs.

Note that the weaker scalar items are strengthened. The second sentence in (56) is most naturally interpreted as "some but not all," and in (57), the speaker must have meant that the hotel's location was good but not exceedingly so. What is remarkable here is that the addition of an overt exhaustive expression, such as only or just, is infelicitous. This is one of the instances in which the implicit exhaustification cannot be paraphrased by adding an overt exhaustive expression, and it will guide the discussion in the next section: Why does the presence of only or just save the otherwise infelicitous order of scalar items in contrast?

\section{COMMENTS ON ONLY}

One notable difference between the current proposal and the previous analyses is the view on the distribution of $\mathrm{O}_{A L T}$. In the account developed here, there is no restriction on it. It can appear, in principle, in the second disjunct in disjunction, provided that a good contrast antecedent is present in the preceding context. Both Singh (2008) and Fox and Spector (2018) attribute the ordering asymmetry to a certain distributional restriction on $\mathrm{O}_{A L T}$, and their approach might come from the following train of thought: (i) $\mathrm{O}_{A L T}$ is the silent version of only, (ii) "all or $\left[\mathrm{O}_{A L T}\right.$ some]" is not good, but "all or only some" is good, (iii) thus, the constraint is about how to regulate $\mathrm{O}_{A L T}$.

Whether these authors indeed had this line of reasoning or not, the issue of only is unavoidable for the contrast based account as well. How does the presence of only or just make the otherwise unnatural order acceptable? My answer to this question begins with the objection to the practice of calling $\mathrm{O}_{A L T}$ the silent version of only. First of all, there are quantifiers that elicit the "not all" interpretations but resist the attachment of only, as discussed in Al Khatib (2013).

(58) Why are the students so upset?

a. Both Professor Suzuki and Professor Tanaka flunked many/most of the students. $\leadsto$ Both professors are such that they did not flunk all of the students.

b. \# Both Professor Suzuki and Professor Tanaka only passed MANY/MOST of the students.

(58a) can seem to generate the local implicature that is paraphrased after $\leadsto$, which means, under the grammaticist system, that $\mathrm{O}_{A L T}$ is inserted below the subject. The operator successfully generates the "not all" implicature. On the other hand, the overt insertion of only is infelicitous in this context ${ }^{21}$. This means that $\mathrm{O}_{A L T}$ can exhaustify when only cannot.

It should also be noted that only some often adds something other than the not-all meaning.

\footnotetext{
${ }^{21}$ The two anonymous reviewers pointed out that only most is acceptable when it is explicitly contrasted with all. In the example above, however, there is no such contrast, but most still generates the relevant scalar implicature.
} 
(59) Did your relatives come to your wedding?

A: Some of them did.

A': Some but not all of them did.

A": Only some of them did.

The answer $\mathrm{A}$ is functionally equivalent to $\mathrm{A}^{\prime}$, as we most naturally understand the meaning of some being strengthened. The equivalence between $\mathrm{A}$ and $\mathrm{A} "$ is much less clear. A" definitely indicates that not all of the relatives came, but it tends to communicate something extra, such as a sense of disappointment. We can highlight the difference by adding "I thought that none of them showed up." The addition is felicitous with Response A, but it is distinctly odd with Response A", as demonstrated below.

(60) Did your relatives come to your wedding?

A: Some of them did. I thought that none them would show up.

A": Only some of them did. \#I thought that none of them would show up.

This extra meaning is related to the scalar use of only, which was noted by Horn (1969). The following sentences exemplify the scalar meaning of only.

(61) a. This time, Usain Bolt only got the bronze medal in the men's $100 \mathrm{~m}$ race.

b. My friend Joshua and I were short-listed for the same job at the company. Joshua had a meeting with the CEO, but I was interviewed only by the vice president.

We all know that for any given category of competition, one individual can receive no more than one medal. Thus, the semantic contribution of only in (61a) is not exhaustivity/exclusivity. Rather, it adds the meaning that what Usain Bolt got this time is a lesser medal than before. Similarly, (61b) can be uttered truthfully even when the speaker was also interviewed by some people other than the vice president. In these instances, only does not negate non-weaker alternatives. It instead indicates that the said content is "lower in the relevant scale" than some standard that was expected or was made salient in the context ${ }^{22}$.

Turning our attention back to scalar items, it is clear that "only + a scalar item" generates the scalar meaning, not the exhaustivity meaning. What happens when "only + a scalar item" is used in a contrastive environment?

a. Anna ate all of the cookies or only some of the cookies.

b. Anna read all of the textbooks, but Bertha read only some of them.

\footnotetext{
${ }^{22}$ Schwarzschild (1996) attempts to provide a uniform analysis of the exhaustive and the scalar uses of only by using the scalar meaning as its base. Similarly, Zeevat (2009) proposes a "mirative" analysis of focus sensitive adverbs, in which the sole semantic contribution of only is the scalar meaning of "less than expected." The alleged exhaustivity meaning in a sentence with only is derivable with focus; even without only, the sentence has the exhaustive meaning, as it is typically considered as the complete exhaustive answer to a QUD.
}

c. While Anna read all of the textbooks, Bertha read only some of them.

In these examples, only some does not demand the presence of a contrast antecedent that provides a mutual exclusive set. Rather, it requires an antecedent that provides the standard of comparison with which the prejacent of only is evaluated. Thus, the meaning of (62a) is paraphrased as Anna ate all of the cookies or she ate some of the cookies, which is lower than some standard in the relevant scale. The relevant scale is most naturally understood to be proportions of the cookies consumed, and the salient standard is eating all the cookies, which the first disjunct provides.

The same strategy works for other scale-mate pairs with only or just.

(63) a. Anna's sister is brilliant, but Anna herself is just smart.

b. Anna's sister is brilliant, but Anna herself is smart, which is lower in the relevant scale than being brilliant. $\leadsto$ Anna is smart but not brilliant.

a. When you ride a motorcycle, wearing a helmet is required in Japan. But in the U.S., it is only recommended.

b. ... But in the U.S., it is only recommended, which is lower in the relevant scale than being required. $\leadsto$ In the U.S., it is recommended but not required.

To sum up, calling $\mathrm{O}_{A L T}$ the silent version of only is more misleading than useful since the overt only is not the kind of exhaustivity operator comparable to $\mathrm{O}_{A L T}$ when it combines with a scalar item. As a consequence, it is not surprising that the distributional pattern of only does not exactly match that of $\mathrm{O}_{A L T}$. In particular, the addition of only improves the less-than-perfect order of two scalar items, and it is due to a different requirement imposed on the contrast antecedent for only.

\section{FINAL THOUGHTS}

This paper presents a novel analysis of Singh's (2008) paradigm of the ordering restriction on scalar items and its interaction with Hurford's Constraint. It is based on the entirely new generalization that the relevant restriction is found not only in disjunction but in contrastive environments in general. I argue that the source of the restriction is rooted in the inherent ordering asymmetry in making contrasts. One important ingredient of the analysis is a mutually exclusive set of alternatives. This concept has been proposed in the past, but its use is extended to regulate the contrastiveness generated by focus. It should also be noted that the proposed account for the ordering asymmetry is applicable to Hurford's Constraint itself, as disjunction is one of the many linguistic environments that evoke the sense of contrastiveness. Singh's Inconsistency Condition on disjuncts is a direct consequence of the mutual exclusiveness requirement on the set of alternatives in contrastive contexts. Another noteworthy aspect of the proposal is that it makes it necessary 
that the scalar meaning, traditionally labeled as a conversational implicature, is grammatically generated so that it can become the basis of computing alternatives.

In the current proposal, disjunction is one sub-type of contrastive environment, and the previous analyses based on the syntax and semantics of disjunction could be considered dispensable. It is predicted, therefore, that there are no disjunction-specific facts in the domain of the ordering restriction. In this regard, there are a few cases, noted by Fox and Spector (2018), that challenge this prediction. According to Fox and Spector, the strong-weak order becomes felicitous when it is under the scope of a universal quantifier, as exemplified in the following minimal pair.

(65) Fox and Spector (52ab)

a. \#Either John did both the reading and the homework or he did the reading or the homework.

b. Either everyone did both the reading and the homework or everyone did the reading or the homework.

I have not succeeded in eliciting solid and consistent judgments on this minimal pair from the native speakers I consulted. If the contrast is as clear as reported in Fox and Spector (2018), it is indeed quite puzzling not only because my proposal has no account to offer but also because it does not seem to carry over to non-disjunctive contrastive environments. For instance, it is hard to find the same kind of contrast in the following pair ${ }^{23}$.

(66) A: Eric did both the reading and the homework.

B: (\#) Not true! He did the reading or the homework.

(67) A: Every student did both the reading and the homework. B: (\#) Not true! Every student did the reading or the homework.

The presence of contrast in (65) and the lack thereof in $(66) /(67)$ would be an unwelcome combination for the current proposal.

Fox and Spector (2018) further note that the all-some order becomes acceptable if the disjunction structure that contains the quantifiers is placed under the scope of such operators as a universal quantifier and an intensional operator.

a. Every student solved all or some of the problems. = Fox and Spector [2018, (58b)]

b. A new Harris Poll finds a plurality of Americans want all or most abortions to be illegal. $=$ Fox and Spector [2018, (60)]

While these examples pose challenges to the current proposal, they are more complex than what they appear to be. Consider the imperative structure in (69), inspired by Fox and Spector's (2018) example (61):

(69) Please tell me all or some of the names of the suspects.

\footnotetext{
${ }^{23}$ In general, the and-or order is judged a little better than the all-some order [e.g., (20)], hence \# is parenthesized. The point here is that there is no discernible contrast between the proper name and the quantified subjects.
}

As predicted by Fox and Spector, the all-some order is acceptable in this example. It seems, however, that the meaning of this sentence does not correspond to the one expected by their analysis. This sentence is more appropriately paraphrased as (70a), rather than (70b) and (70c), which suggests that what is involved in this disjunction is not the straightforward application of $O_{A L T}$.

(70) a. Please tell me all or at least some of the names of the suspects.

b. Please tell me all or only some of the names of the suspects.

c. Please tell me all or some but not all of the names of the suspects.

The most natural interpretation of (69) indicates that the first disjunct is the preferred choice, but if that cannot be achieved, the second option is still acceptable. Closer inspection reveals that this "concessive-like" meaning is also relevant in the abortion example (68b). The sentence can depict the following situation: some of those Americans want all abortions to be illegal, but others, while they want most abortions to be illegal, have some conflicted feelings about a small number of exceptional cases. For those people, it is too strong to say that they want most but not all abortions to be illegal, as they cannot decide whether the exceptional cases should be legal or illegal. A proper analysis of this type of disjunction should begin with the assumption that it is not a part of the generalization based on Hurford's Constraint since the meaning, which is paraphrased as "all or at least some," seems to violate the constraint in the first place. Incidentally, non-disjunctive environments also allow the all-some order if a similar, "concessive-like" relation is expressed.

(71) a. If you cannot tell me all the names of the suspects, please tell me some of them.

b. A: Are you asking me to tell you all the names of the suspects? You know that I can't.

B: OK, then, can you tell me some of their names?

If these concessive-like cases are set aside as independent problems, there remain only a small set of disjunction-specific puzzles, such as (65) and (68a), that go beyond the contrastbased analysis that I advocate in this paper. They involve rather subtle and variable judgments, however. Closer and more rigorous examination of the data is needed for the current proposal to move forward, and experimental research will be particularly welcome.

\section{DATA AVAILABILITY STATEMENT}

All datasets generated for this study are included in the article and the supplementary material.

\section{AUTHOR CONTRIBUTIONS}

The author confirms being the sole contributor of this work and has approved it for publication. 


\section{REFERENCES}

Al Khatib, S. (2013). 'Only' and association with negative antonyms (Ph.D. thesis). Cambridge, MA: MIT.

Asher, N., and Lascarides, A. (2003). Logics of Conversation. Cambridge: Cambridge University Press.

Beck, S., and Sharvit, Y. (2002). Pluralities of questions. J. Seman. 19, 105-157. doi: 10.1093/jos/19.2.105

Blakemore, D., and Carston, R. (2005). The pragmatics of sentential coordination with and. Lingua 115, 569-589. doi: 10.1016/j.lingua.2003. 09.016

Büring, D. (1997). The great scope inversion conspiracy. Linguist. Philos. 20, 175-194. doi: 10.1023/A:1005397026866

Büring, D. (2003). On d-trees, beans, and b-accents. Linguist. Philos. 26, 511-545. doi: 10.1023/A:1025887707652

Chierchia, G. (2004). "Scalar implicatures, polarity phenomena and the syntax/pragmatics interface," in Structures and Beyond: The Cartography of Syntactic Structure, Vol. 3, ed A. Belletti (Oxford: Oxford University Press), 39-103.

Chierchia, G. (2006). Broaden your views: Implicatures of domain widening and the "logicality" of language. Linguist. Inq. 37, 535-590. doi: 10.1162/ling.2006.37.4.535

Chierchia, G., Fox, D., and Spector, B. (2012). "The grammatical view of scalar implicatures and the relationship between semantics and pragmatics," in Semantics: An International Handbook of Natural Language Meaning, eds K. von Heusinger, C. Maienborn, and P. Portner (Berlin: de Gruyter).

Fox, D. (2000). Economy and Semantic Interpretation. Cambridge, MA: MIT Press and MIT Working Papers in Linguistics.

Fox, D. (2007). "Free choice and the theory of scalar implicatures," in Presupposition and Implicature in Compositional Semantics, eds U. Sauerland and P. Stateva (Basingstoke: Palgrave Macmillan), 71-120. doi: 10.1057/9780230210752_4

Fox, D., and Katzir, R. (2011). On the characterization of alternatives. Nat. Lang. Seman. 19, 87-107. doi: 10.1007/s11050-010-9065-3

Fox, D., and Spector, B. (2018). Economy and embedded exhaustification. Nat. Lang. Seman. 26, 1-50. doi: 10.1007/s11050-017-9139-6

Gazdar, G. (1979). Pragmatics: Implicature, Presupposition, and Logical Form. New York, NY: Academic Press.

Geurts, B. (2010). Quantity Implicatures. Cambridge: Cambridge University Press. doi: 10.1017/CBO9780511975158

Horn, L. (1969). "A presuppositional analysis of only and even," in Papers from the Fifth Regional Meeting of the Chicago Linguistic Society (Chicago, IL), 97-108.

Horn, L. (1972). On the semantic properties of the logical operators in English (Ph.D. thesis). Los Angeles, CA: UCLA.

Horn, L. R. (1989). A Natural History of Negation. Chicago, IL; London: The University of Chicago Press.

Hurford, J. (1974). Exclusive or inclusive disjunction. Found. Lang. 11, 409-411.

Katzir, R. (2007). Structurally-defined alternatives. Linguist. Philos. 30, 669-690. doi: 10.1007/s10988-008-9029-y

Kehler, A. (2002). Coherence, Reference, and the Theory of Grammar. Stanford, CA: CSLI Publications.

Lee, C. (2007). "Contrastive (predicate) topic, intonation, and scalar meanings," in Topic and Focus: Cross-Linguistic Perspectives on Meaning and Intonation, eds
C. Lee and M. Gordon (Berlin: Springer Science \& Business Media), 151-175. doi: 10.1007/978-1-4020-4796-19

Levinson, S. C. (2000). Presumptive Meanings. Cambridge, MA: MIT Press. doi: 10.7551/mitpress/5526.001.0001

Matsumoto, Y. (1995). The conversational condition on horn scales. Linguist. Philos. 18, 21-60. doi: 10.1007/BF00984960

Menéndez-Benito, P. (2010). On universal free choice items. Nat. Lang. Seman. 18, 33-64. doi: 10.1007/s11050-009-9050-x

Roberts, C. (1996). "Information structure in discourse: towards an integrated formal theory of pragmatics," Ohio State University Working Papers in Linguistics, eds J. H. Yoon and A. Kathol (Columbus, OH), 91-136.

Rooth, M. (1992). A theory of focus interpretation. Nat. Lang. Semant. 1, 117-121. doi: $10.1007 / \mathrm{BF} 02342617$

Sæbø, K. J. (2003). "Presupposition and contrast: German aber as a topic particle," in Proceedings of Sinn und Bedeutung, 257-271.

Sauerland, U. (2004). Scalar implicatures in complex sentences. Linguistics and Philosophy, 27:343-377. doi: 10.1023/B:LING.0000023378.71748.db

Sauerland, U. (2012). The computation of scalar implicatures: pragmatic, lexical or grammatical? Lang. Linguist. Compass 6, 36-49. doi: 10.1002/lnc3.321

Sauerland, U. (2014). "Intermediate scalar implicatures," in Pragmatics, Semantics and the Case of Scalar Implicatures, ed S. P. Reda (Basingstoke: Palgrave Macmillan), 72-98. doi: 10.1057/9781137333285_4

Schwarzschild, R. (1996). Givenness and optimal focus (Ms.). New Brunswick, NJ: Rutgers University.

Singh, R. (2008). On the interpretation of disjunction: asymmetric, incremental, and eager for inconsistency. Linguist. Philos. 31, 245-260. doi: $10.1007 /$ s10988-008-9038-x

Tomioka, S. (2010). "Contrastive topics operate on speech acts," in Information Structure from Different Perspectives, eds M. Zimmermann and F. Caroline (Oxford: OUP), 753-773.

Tomioka, S. (2019). The scope of contrasted scalar items and intermediate implicatures. English Linguist. 36, 29-47.

Umbach, C. (2005). Contrast and information structure: a focus-based analysis of but. Linguistics 43, 207-232. doi: 10.1515/ling.2005.43.1.207

Wagner, M. (2012). "Focus and givenness: a unified approach," in Contrasts and Positions in Information Structure, eds I. Kučerová and A. Neeleman (Cambridge: Cambridge University Press), 102-147. doi: 10.1017/CBO9780511740084.007

Winterstein, G. (2012). What but-sentences argue for: an argumentative analysis of but. Lingua 122, 1864-1885. doi: 10.1016/j.lingua.2012.09.014

Zeevat, H. (2009). "Only" as a mirative particle," in Focus at the Syntax-Semantics Interface: Working Papers of the SFB 732, Vol. 3, ed A. R. Onea (Stuttgart: Stuttgart University), 121-141.

Conflict of Interest: The author declares that the research was conducted in the absence of any commercial or financial relationships that could be construed as a potential conflict of interest.

Copyright (c) 2021 Tomioka. This is an open-access article distributed under the terms of the Creative Commons Attribution License (CC BY). The use, distribution or reproduction in other forums is permitted, provided the original author(s) and the copyright owner(s) are credited and that the original publication in this journal is cited, in accordance with accepted academic practice. No use, distribution or reproduction is permitted which does not comply with these terms. 